Применение комбинации атезолизумаба и химиотерапии в 1-й линии метастатического мелкоклеточного рака легкого. Клинический опыт

\author{
Н.А. Огнерубов $₫ 1,2$, Т.С. Антипова ${ }^{3}$ \\ ${ }^{1}$ ФГБОУ В0 «Тамбовский государственный университет им. Г.Р. Державина», Тамбов, Россия; \\ 2ГБУЗ «Тамбовский областной онкологический клинический диспансер», Тамбов, Россия; \\ ${ }^{3} 000$ «ПЭТ-Технолоджи», Центр ядерной медицины, Тамбов, Россия
}

\begin{abstract}
Аннотация
Обоснование. Рак легкого (РЛ) занимает лидирующее положение среди злокачественных опухолей в мире, на его долю приходится 11,4\% злокачественных новообразований. В 2020 г. в мире выявлен 2206771 новый случай РЛ и 1796144 смерти от него. Среди различных гистологических вариантов мелкоклеточный РЛ (МКРЛ) является самым неблагоприятным. Он считается высокочувствительным к химиотерапии. Несмотря на определенные успехи в терапии этого заболевания, результаты лечения остаются малоутешительными. В последние годы применение ингибиторов контрольных точек иммунного ответа обеспечило значимый контроль течения заболевания.

Цель. Показать эффективность применения атезолизумаба в комбинации с химиотерапией при метастатическом МКРЛ. Материалы и методы. Под наблюдением находился пациент 76 лет с диагнозом: рак левого легкого, ст. IVA T4N3M1b, метастазы в надключичный лимфоузел справа, экссудативный плеврит слева. При гистологическом исследовании установлен МКРЛ. Метастазы в головной мозг не выявлены. ECOG 0.

Результаты. Пациенту проводили лечение по схеме атезолизумаб 1200 мг вместе с карбоплатином 5 AUC и этопозидом 100 мг/м² 1-3-й день в количестве 4 циклов с последующим переходом на поддерживающую терапию атезолизумабом 1200 мг каждый 21-й день. Больной получил 21 введение на протяжении 14 мес. Оценка эффекта лечения осуществлялась с

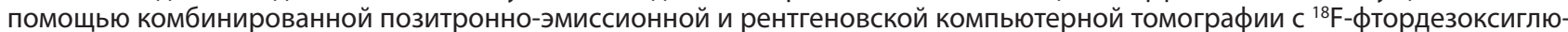
козой. В результате проведенного лечения через 7 мес получена полная клиническая и морфо-метаболическая регрессия опухоли, которая сохраняется на протяжении всего периода лечения. Из нежелательных явлений отмечались анемия 2-й степени и сенсорная нейропатия 1-й степени. Иммуноопосредованных побочных реакций не наблюдалось.

Заключение. Добавление атезолизумаба к химиотерапии этопозид + карбоплатин в качестве терапии 1-й линии распространенного МКРЛ обеспечивает длительную общую и безрецидивную выживаемость, сохраняя при этом удовлетворительное качество жизни пациентов и приемлемую переносимость препаратов.
\end{abstract}

Ключевые слова: мелкоклеточный рак легкого, ингибиторы контрольных точек PD-1/PD-L1, атезолизумаб, комбинированная позитронно-эмиссионная и рентгеновская компьютерная томография

Для цитирования: Огнерубов Н.А., Антипова Т.С. Применение комбинации атезолизумаба и химиотерапии в 1-й линии метастатического мелкоклеточного рака легкого. Клинический опыт. Современная Онкология. 2021; 23 (2): $292-298$.

DOI: 10.26442/18151434.2021.2.200965

\section{Введение}

Рак легкого (РЛ) по распространенности занимает лидирующее положение среди всех злокачественных новообразований (3НО) в мире. По данным GLOBOCAN, в 2020 г. в мире выявлен 2206771 новый случай рака (11,4\% всех 3НО) и 1796144 случая смерти - 18\% [1].

В России в 2019 г. РЛ занимал 3-е место в структуре заболеваемости злокачественными опухолями - 60113 новых случаев [2]. При этом он является основной причиной смерти 50046 случаев. Гендерные различия выражены: у мужчин он занимает 1-е место (25\%), а у женщин - 10 -е место $(4,3 \%)$.

РЛ по морфологической структуре является гетерогенным заболеванием. На долю аденокарциномы приходится $40 \%$, а мелкоклеточный РЛ (МКРЛ) составляет 15\% [3]. Почти $2 / 3$ пациентов с МКРЛ имеют распространенную стадию опухолевого процесса, что связано с плохим прогнозом. При этом 5-летняя выживаемость составляет 2,9-7,5\% [4].

МКРЛ является высокочувствительным к химиотерапии. Начиная с 1985 г. основной опцией его лечения была схема, содержащая цисплатин и этопозид, а с 1995 г. - карбоплатин и этопозид [5-8], применение которой первоначально обеспечи- вало высокую частоту объективного ответа (ЧОО). Однако, несмотря на это, медиана выживаемости пациентов составляла около 10 мес [9].

Последние годы ознаменовались появлением прорывной технологии - иммуноонкологии в лечении ЗНО, включая и РЛ. Применение ингибиторов контрольных точек (ИКТ) иммунного ответа CTLA4, PD-1/PD-L1 при МКРЛ позволило получить увеличение как общей $(\mathrm{OB})$, так и безрецидивной выживаемости при обширных стадиях опухолевого процесса [10-14].

Ниже мы приводим собственный опыт длительного применения ИКТ иммунного ответа PD-1/PD-L1 атезолизумаба в комбинации с этопозидом и платиной у больного с метастатическим МКРЛ.

\section{Клиническое наблюдение}

Больной П., 76 лет. Обратился в феврале 2020 г. с жалобами на повышение температуры тела до $37,2-37,6^{\circ} \mathrm{C}$, слабость, похудение на 5 кг, сухой кашель. Указанные симптомы появились за 1 мес до обращения. Объективно: ECOG 0. Пациент работает (главный специалист предприятия). Питание понижено. Кожные покровы обычной окраски, на ощупь сухие.

\section{Информация об авторах / Information about the authors}

Огнерубов Николай Алексеевич - д-р мед. наук, канд. юрид. наук, проф., зав. каф. онкологии Медицинского института ФГБОУ ВО «ТГУ им. Г.Р. Державина», зам. глав. врача по КЭР ГБУЗ ТООКД, засл. работник высшей школы РФ, засл. врач РФ. E-mail: ognerubov_n.a@mail.ru; ORCID: 0000-0003-4045-1247; SPIN-код: 3576-3592; Author ID: 632250

Антипова Татьяна Сергеевна - врач 000 «ПЭТ-Технолоджи», Центр ядерной медицины. E-mail: antipovats@gmail.com; 0RCID: 0000-0003-4165-8397
Nikolai A. Ognerubov - D. Sci. (Med.), Cand. Sci. (Law), Prof., Derzhavin Tambov State University, Tambov Regional Oncological Clinical Dispensary. E-mail: ognerubov_n.a@mail.ru; ORCID: 0000-0003-4045-1247; SPIN code: 3576-3592; Author ID: 632250

Tatyana S. Antipova - doctor, "PET-Technoligy” Ltd, Nuclear Medicine Center. E-mail: antipovats@gmail.com; ORCID: 0000-0003-4165-8397 


\title{
The use of atezolizumab in combination with chemotherapy in first-line of metastatic small cell lung cancer. Case report
}

\author{
Nikolai A. Ognerubov ${ }^{\bowtie 1,2}$, Tatyana S. Antipova ${ }^{3}$ \\ 'Derzhavin Tambov State University, Tambov, Russia; \\ ${ }^{2}$ Tambov Regional Oncological Clinical Dispensary, Tambov, Russia; \\ 3"PET-Technoligy" Ltd, Nuclear Medicine Center, Tambov, Russia
}

\begin{abstract}
Background. Lung cancer (LC) occupies a leading position among malignant tumors in the world, it accounts for $11.4 \%$ of the total malignant neoplasms. In 2020, there were 2206771 new cases of LC and 1796144 deaths worldwide. Among the histological variants, small cell LC (SCLC) has the most unfavorable outcomes. This variant is considered highly sensitive to chemotherapy. Despite some successes in the treatment of this disease, the results of treatment remain problematical. In recent years, the use of immune checkpoint inhibitors has provided significant control of the course of the disease.

Aim. To show the efficacy of atezolizumab in combination with chemotherapy in patients with metastatic SCLC.

Materials and methods. A 76-year-old patient with left lung cancer, IVA T4N3M1b, the right supraclavicular lymph node metastases, exudative pleuritis of the left lung was under observation. The histological investigation showed SCLC. Brain metastases were not detected. ECOG 0.

Results. The patient was treated using atezolizumab $1200 \mathrm{mg}$ in combination with carboplatin 5 AUC and etoposide $100 \mathrm{mg} / \mathrm{m}^{2}$ on days 1, 2, 3 for four cycles, followed by a maintenance therapy regimen with atezolizumab 1200 mg every 21 days. The patient received 21 injections during 14 months. The assessment of treatment effect was evaluated using combined ${ }^{18} \mathrm{~F}$-fluorodeoxyglucose positron emission and X-ray computed tomography. As a result of the treatment, after 7 months, a complete clinical and morpho-metabolic regression of the tumor was reached, which persisted throughout the period of the treatment. Among the adverse events were detected grade 2 anemia and first-stage sensory neuropathy. No immune-related adverse events were observed. Conclusion. The addition of atezolizumab to etoposide + carboplatin as the first-line therapy for extensive-stage SCLC provides the long-term overall and disease-free survival with achieving the satisfactory quality of life in patients and acceptable drug tolerance.
\end{abstract}

Keywords: small cell lung cancer, PD-1/PD-L1 checkpoint inhibitors, atezolizumab, combined positron emission and X-ray computed tomography

For citation: Ognerubov NA, Antipova TS. The use of atezolizumab in combination with chemotherapy in first-line of metastatic small cell lung cancer. Case report. Journal of Modern Oncology. 2021; 23 (2): 292-298. DOI: 10.26442/18151434.2021.2.200965

Пульс 71 уд/мин, ритмичный. Артериальное давление 140/80 мм рт. ст. В надключичной области справа пальпируется лимфатический узел размером $1,8 \times 1,2$ см, плотный, метастатического характера, подвижность ограничена. Подмышечные лимфоузлы с обеих сторон размером до $0,9 \times 0,5$ см, эластической консистенции, подвижные, безболезненные. При перкуссии в легких - легочный звук, слева, начиная с VII ребра, отмечается его укорочение. При аускультации - везикулярное дыхание, ослабленное слева в нижних отделах, начиная с VII ребра. Физиологические отправления не нарушены. Курит с 16 лет по 1 пачке сигарет в сутки.

Проведено обследование. Эхокардиография: фракция выбро$\mathrm{ca}-55 \%$. Сочетанный аортальный порок сердца, значительный стеноз, незначительная недостаточность аортального клапана.

Спиральная компьютерная томография (KT) грудной клетки: КТ-картина центрального рака в корне левого легкого, опухолевый конгломерат $68 \times 45 \times 96$ мм, с ателектазом S10 нижней доли левого легкого, метастазы в бронхопульмональные слева и медиастинальные лимфоузлы, с левосторонним плевритом. Заключение: картина центрального рака левого легкого. Бронхоскопия - перибронхиальный рак левого легкого, произведена биопсия. При гистологическом исследовании выявлена мелкоклеточная карцинома.

Комбинированная позитронно-эмиссионная и рентгеновская КТ (ПЭТ/КТ) с ${ }^{18} \mathrm{~F}$-фтордезоксиглюкозой (ФДГ): патологическое образование в нижней доле левого легкого S10 размером $41 \times 57 \times 81$ мм, SUVmax 10,75 . В надключичной области справа определяется увеличенный метаболически активный лимфоузел размером до 14×9 мм, SUVmax 7,82. Увеличены паратрахеальные, бифуркационные, бронхопульмональные лимфоузлы (SUVmax 11,20), лимфоузлы аортопульмонального окна размером до $21 \times 45$ мм, SUVmax 10,53 . В головном мозге в режиме рентгеновской КТ очаговых образований не выявлено. Экссудативный плеврит слева (рис. 1).
Установлен окончательный диагноз: рак левого легкого, стадия IVA T4N3M1b, метастазы в надключичный лимфоузел справа, экссудативный плеврит слева.

Учитывая распространенность опухолевого процесса, а также вариант гистологического строения, больному назначена иммунотерапия атезолизумабом 1200 мг в комбинации с карбоплатином AUC 5 и этопозидом 100 мг/м² 1-3-й день.

Выполнена магнитно-резонансная томография головного мозга - данных по поводу метастатического поражения головного мозга не выявлено.

После 3-го цикла произведена мультиспиральная КТ грудной клетки. Отмечено уменьшение опухоли левого корня и S10: очаговые образования 16 мм, $17 \times 13$ мм с тяжами к левому корню, разрешение плеврита слева, уменьшение лимфоузлов средостения. По критериям RECIST v.1.1 получена частичная регрессия. Такая комбинация атезолизумаба с химиотерапией проведена на протяжении 4 циклов. В последующем вводился атезолизумаб в дозе 1200 мг каждый 21-й день.

После 6-го введения атезолизумаба выполнена ПЭТ/КТ с ${ }^{18} \mathrm{~F}-\Phi Д Г$. Выраженная положительная динамика за счет сокращения размеров опухоли в нижней доле левого легкого до $15 \times 16 \times 15$ мм (ранее $41 \times 57 \times 81$ мм) без метаболической активности ${ }^{18} \mathrm{~F}-Ф Д Г$. Восстановление объема легочной ткани левого легкого. В S10 на месте ателектаза сформировался пневмофиброз в виде узлового образования размером до $15 \times 16$ мм, без метаболической активности ${ }^{18} \mathrm{~F}-\Phi Д Г$. Отмечается уменьшение размеров паратрахеальных, бифуркационных лимфоузлов, включая аортопульмональное окно без фиксации радиофармпрепарата (РФП). В головном мозге в режиме рентгеновской КТ очаговых образований не выявлено (рис. 2).

По окончании 7-го введения атезолизумаба по данным магнитно-резонансной томографии головного мозга очаговой патологии не выявлено. 
Рис. 1. Больной П., 76 лет, до лечения. На МІР- и аксиальных ПЭТ/КТ-проекциях определяется увеличенный метаболически активный надключичный лимфоузел справа размером до 14×9 мм, SUVmax 7,82. На фоне ателектаза нижней доли левого легкого в S10 визуализируется объемное образование (желтая стрелка), распространяющееся к корню, общим размером до 41×57×81 мм, прилегающее кзадней костальной и паравертебральной плевре, сповышенной метаболической активностью ФДГ (SUVmax 10,75). Увеличены паратрахеальные,

бифуркационные, бронхопульмональные лимфоузлы (SUVmax 11,20), лимфоузлы аортопульмонального окна размером до 21×45 мM, SUVmax 10,53 (красная стрелка).

Fig. 1. A 76-year-old patient P. before the treatment. MIP and axial PET/CT images show an enlarged metabolically active right supraclavicular lymph node measuring $14 \times 9 \mathrm{~mm}, \mathrm{SUVmax} 7.82$. Against the background of atelectasis of the left lower lobe, a tumor mass formation (yellow arrow) is visualized in 510 , extending to the root of the lung, with a total size measuring $41 \times 57 \times 81 \mathrm{~mm}$ adjacent to the posterior costal and paraspinal pleura, with increased FDG metabolic activity (SUVmax 10.75). Enlarged paratracheal, bifurcation, bronchopulmonary lymph nodes (SUVmax 11.20) and aortopulmonary window lymph nodes measuring $21 \times 45 \mathrm{~mm}$, SUVmax 10.53 (red arrow) is detected.

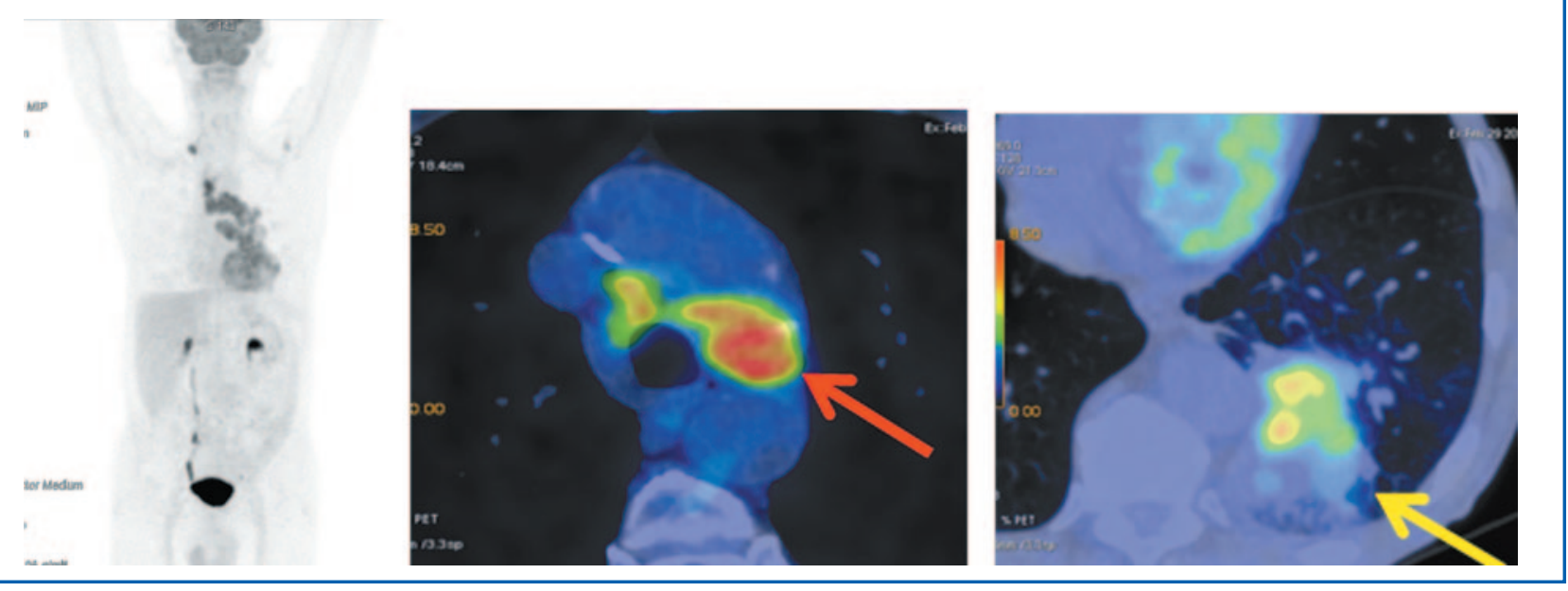

Рис. 2. Больной П., 76 лет, после 6 введений атезолизумаба (через 3 мес от начала лечения). На МІР- и аксиальных Пэт/КТ-проекциях отмечается регрессия надключичного лимфоузла справа. Вентиляция легочной ткани левого легкого восстановлена. B S10 на месте ателектаза сформировался пневмофиброз с включением узлового образования в структуру размером до 15×16×15 мм (ранее размером до 41×57×81 мм) с четким контуром без метаболической активности ФДГ (желтая стрелка). В плевральных полостях и полости перикарда экссудата нет. Размеры паратрахеальных, бифуркационных узлов и аортопульмонального окна уменьшились без фиксации РФП (красная стрелка).

Fig. 2. A 76-year-old patient P. after 6 injections of atezolizumab ( 3 months after the start of treatment). MIP and axial PET/CT images show the regression of the right supraclavicular lymph node. Right lung ventilation is restored. In 510 the pneumofibrosis at the site of atelectasis with a nodular formation in a structure measuring $15 \times 16 \times 15 \mathrm{~mm}$ (previously measuring $41 \times 57 \times 81 \mathrm{~mm}$ ) with the clear margins without FDG metabolic activity (yellow arrow) is detected. There is no exudate in the pleural and pericardial cavities. The size of paratracheal, bifurcation and aortopulmonary window lymph nodes decreased and without uptake of the RFP (red arrow).
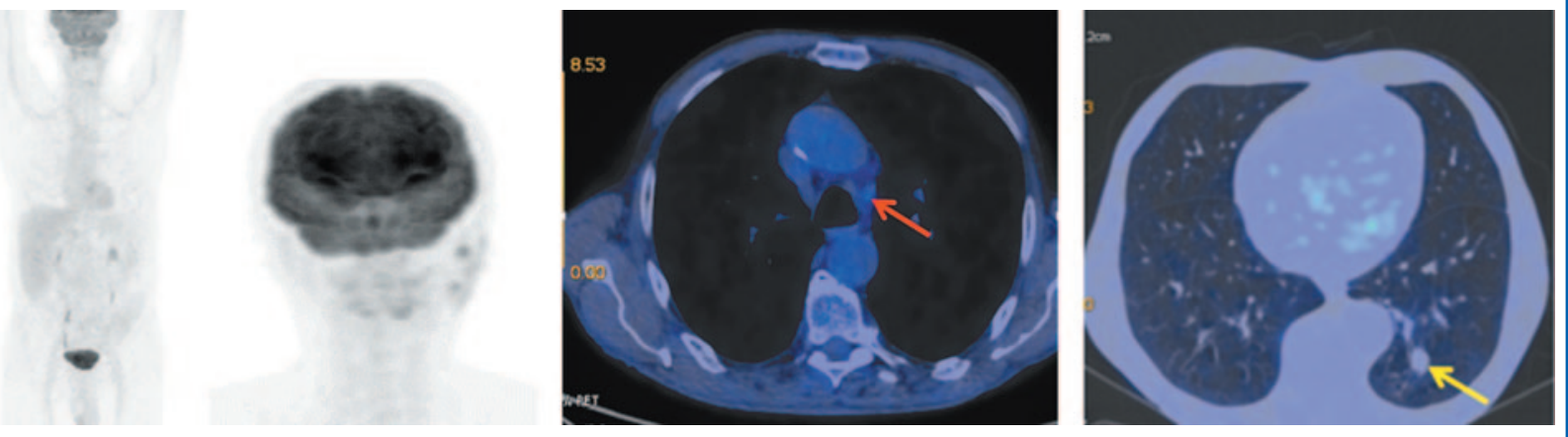

Рис. З. Больной П., 76 лет, после 10 введений атезолизумаба (через 6 мес от начала лечения). На МІР- и аксиальных ПЭТ/КТ-проекциях надключичный лимфоузел справа не визуализируется. В нижней доле левого легкого на месте патологического образования определяется тяж фиброза с узловым образованием (желтая стрелка) в структуре размером до 13×14 мм (ранее 15×16 мм) без метаболической активности ФДГ. Отмечается регресс цепочки паратрахеальных лимфоузлов с верхнего уровня до бифуркации. Лимфоузлы аортопульмонального окна размером до 10×12 мм (красная стрелка).

Fig. 3. A 76-year-old patient P. after 10 injections of atezolizumab (6 months after the start of treatment). MIP and axial PET/CT images did not show the right supraclavicular lymph. In the lower lobe of the left lung at the site of the pathological lesion, a band of fibrous tissue with a nodular formation (yellow arrow) is determined in a structure measuring $13 \times 14 \mathrm{~mm}$ (previously $15 \times 16 \mathrm{~mm}$ ) without FDG metabolic activity. There is a regression of the paratracheal lymph nodes from the upper level to the bifurcation. Aortopulmonary window lymph nodes are measuring $10 \times 12 \mathrm{~mm}$ (red arrow).
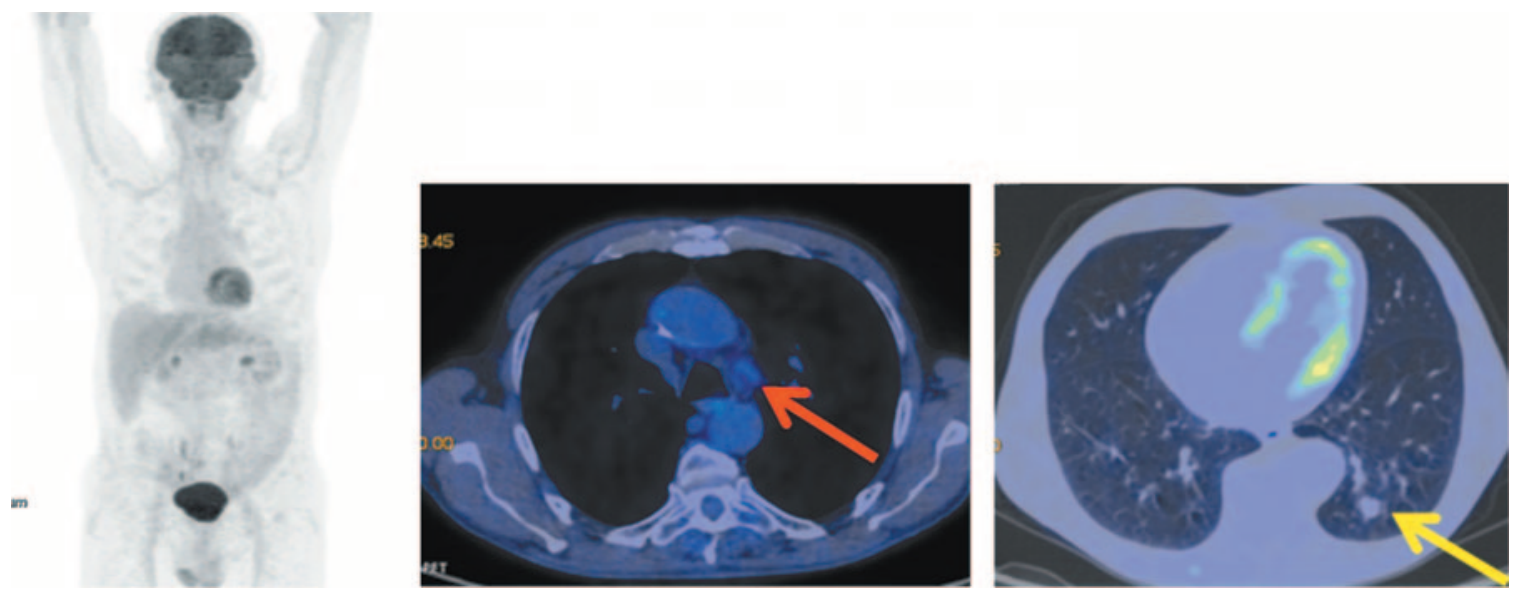
Рис. 4. Больной П., 76 лет, после 16 введений атезолизумаба (через 10 мес от начала лечения). На МІР- и аксиальных ПЭТ/КТ-проекциях в нижней доле левого легкого сохраняется тяж фиброза с узловым образованием в структуре размером до 12×10 мм без метаболической активности ФДГ. Сохраняются лимфоузлы аортопульмонального окна размером до 10 мм с фоновой фиксацией РФП.

Fig. 4. A 76-year-old patient P. after 16 injections of atezolizumab (10 months after the beginning of treatment). A band of fibrous tissue with a nodular formation in a structure measuring $12 \times 10 \mathrm{~mm}$ without FDG metabolic activity in the lower lobe of the left lung is still detected on MIP- and axial PET/CT images. Aortopulmonary window lymph nodes measuring $10 \mathrm{~mm}$ with focal RFP uptake are still detected.
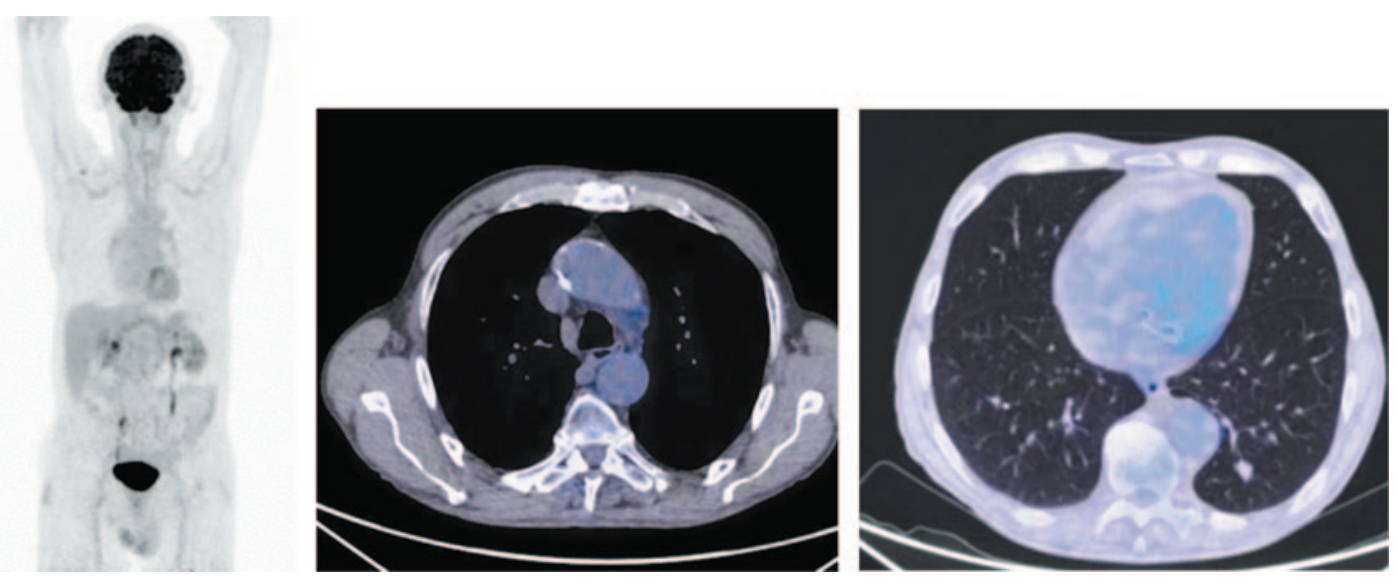

Рис. 5. Больной П., 76 лет, после 20 введений атезолизумаба (через 13 мес от начала лечения). На МІР- и аксиальных ПЭт/КТ-проекциях в нижней доле левого легкого сохраняется тяж фиброза сузловым образованием в структуре прежней конфигурации размером до 12×10 мм без метаболической активности ФДГ и лимфоузлы аортопульмонального окна с фоновой фиксацией РФП.

Fig. 5. A 76-year-old patient P. after 20 injections of atezolizumab (after 13 months from the beginning of treatment). A band of fibrous tissue with a nodular formation in a structure of the same configuration measuring $12 \times 10 \mathrm{~mm}$ without FDG metabolic activity and aortopulmonary window lymph nodes with focal RFP uptake in the lower lobe of the left lung are still detected on MIP- and axial PET/CT images.
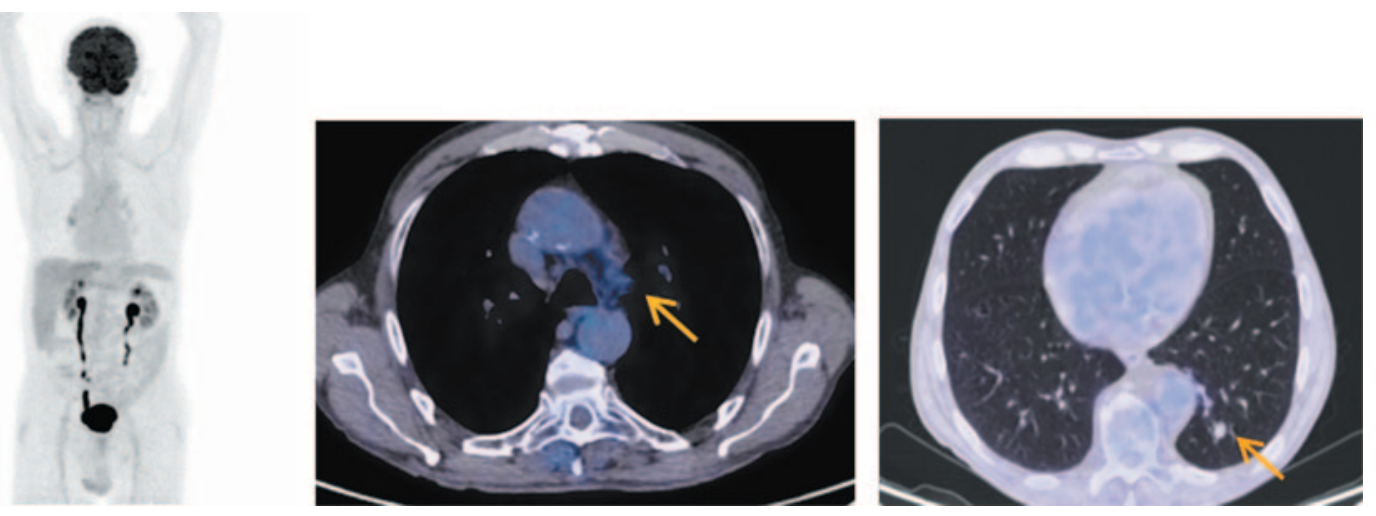

После 10-го введения атезолизумаба (через 7 мес от начала лечения) произведено ПЭТ/КТ-исследование. Объем нижней доли левого легкого восстановлен. На месте патологического образования отмечается фиброзный тяж без метаболической активности ФДГ. Надключичный лимфатический узел справа не определяется. В плевральных полостях и полости перикарда экссудата нет. Лимфоузлы средостения не выявлены (рис. 3). Отмечается полная регрессия опухоли по критериям RECIST v.1.1. и полный морфо-метаболический ответ по результатам ПЭТ/КТ.

Продолжалась поддерживающая терапия атезолизумабом в дозе 1200 мг каждый 21-й день. Клинически признаков прогрессирования не отмечалось. После 16-го введения атезолизумаба выполнена очередная ПЭТ/КТ. В нижней доле левого легкого сохраняется тяж фиброза с узловым образованием в структуре размером до $12 \times 10$ мм без метаболической активности ФДГ. Сохраняются лимфоузлы аортопульмонального окна размером до 10 мм с фоновой фиксацией РФП (рис. 4). B соответствии с критериями RECIST v.1.1 у больного сохраняется полная регрессия опухолевого процесса, а по данным ПЭТ/КТ - полный морфо-метаболический ответ.

После 20-го введения атезолизумаба в дозе 1200 мг выпол-

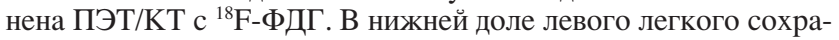
няется тяж фиброза с узловым образованием в структуре прежней конфигурации и размером до $12 \times 10$ мм без метаболической активности ФДГ, равно как и лимфоузлы аортопульмонального окна с фоновой фиксацией РФП. По крите- риям RECIST v.1.1 у пациента сохраняется полная регрессия и полный морфо-метаболический ответ (рис. 5).

В приведенном случае пациенту вводили атезолизумаб в дозе 1200 мг внутривенно каждые 3 нед вначале совместно с карбоплатином и этопозидом на протяжении 4 циклов, а затем в качестве поддерживающей терапии в дозе 1200 мг каждые 3 нед, которая продолжается и в настоящее время. Больной получил 21 введение атезолизумаба в течение 14 мес.

Из нежелательных явлений (НЯ) следует отметить анемию 2-й степени после 2-го цикла лечения и сенсорную нейропатию 1-й степени по окончании 3-го цикла. Применение указанной терапевтической опции позволило достичь полной регрессии опухоли, включая морфо-метаболический ответ, оцениваемый

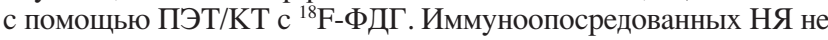
зафиксировано.

Качество жизни у пациента сохранено, он ведет активную физическую деятельность, сохраняет прежний социальный статус.

\section{Обсуждение}

МКРЛ является самым неблагоприятным, высокоагрессивным вариантом, склонным к раннему метастазированию.

Высокий пролиферативный индекс МКРЛ определяет его высокую химио- и радиочувствительность, применение которых обеспечивает быстрый эффект. При распространенном опухолевом процессе прогрессирование заболевания неизбежно. Медиана выживаемости составляет менее 6 мес [8]. 


\begin{tabular}{|c|c|c|}
\hline Показатели & Атезолизумаб + карбоплатин + этопозид & Плацебо + карбоплатин + этопозид \\
\hline Медиана ОВ, мес & 12,3 & 10,3 \\
\hline 95\% ДИ & $10,8-15,8$ & $9,3-11,3$ \\
\hline OP & \multicolumn{2}{|c|}{$0,76(0,60-0,95)$} \\
\hline Медиана ВБП, мес & 5,2 & 4,3 \\
\hline 95\% ДИ & $4,4-5,6$ & $4,2-4,5$ \\
\hline OP & \multicolumn{2}{|c|}{$0,77(0,63-0,95)$} \\
\hline $400, \%$ & 60,2 & 64,4 \\
\hline 95\% ДИ & $53,1-67$ & $57,3-71$ \\
\hline Медиана продолжительности ответа, мес & 4,2 & 3,9 \\
\hline 95\% ДИ & $4,1-4,5$ & $3,1-4,2$ \\
\hline OP & \multicolumn{2}{|c|}{$0,67(0,51-0,88)$} \\
\hline
\end{tabular}

\begin{tabular}{|c|c|c|c|c|}
\hline Исследование & IMpower133 & CASPIAN & KEYNOTE-604 & ECOG-ACRIN EA5161 \\
\hline Авторы & {$[10,25]$} & {$[12,28]$} & {$[29,30]$} & [17] \\
\hline Фаза исследования & $\mid-I I I$ & III & III & II \\
\hline Вид исследования & Двойное слепое & Открытое & Двойное слепое & Открытое \\
\hline Препараты платины & Карбоплатин AUC 5 & $\begin{array}{l}\text { Карбоплатин AUC 5-6, } \\
\text { цисплатин 75-80 мг/м² }\end{array}$ & $\begin{array}{l}\text { Карбоплатин AUC 5-6, } \\
\text { цисплатин } 75 \text { мг/M² }\end{array}$ & 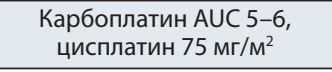 \\
\hline Этопозид, мг/м² & 100 & $80-100$ & 100 & 100 \\
\hline $\begin{array}{l}\text { Исследовательский } \\
\text { препарат, мг }\end{array}$ & Атезолизумаб, 1200 & Дурвалумаб, 1500 & Пембролизумаб, 200 & Ниволумаб, 360 \\
\hline Контрольная группа & Плацебо & - & Плацебо & - \\
\hline $\begin{array}{l}\text { Продолжительность } \\
\text { лечения }\end{array}$ & $\begin{array}{c}4 \text { цикла ПХТ } \\
\text { с поддерживающей } \\
\text { терапией } \\
\text { атезолизумабом/плацебо }\end{array}$ & $\begin{array}{c}6 \text { циклов ПХТ, } 4 \text { цикла } \\
\text { комбинированной терапии } \\
\text { с поддерживающей } \\
\text { терапией дурвалумабом } \\
\text { каждые } 4 \text { нед }\end{array}$ & $\begin{array}{c}4 \text { цикла ПХТ, } \\
\text { поддерживающая терапия } \\
\text { пембролизумабом/ } \\
\text { плацебо до } 35 \text { циклов }\end{array}$ & $\begin{array}{c}4 \text { цикла ПХТ, } 4 \text { цикла } \\
\text { комбинированной терапии } \\
\text { с поддерживающей } \\
\text { терапией ниволумабом } \\
240 \text { мг каждые } 2 \text { нед }\end{array}$ \\
\hline $\begin{array}{l}\text { Первичные конечные } \\
\text { точки }\end{array}$ & ОВ, ВБП & $O B$ & ОВ, ВБП & ВБП \\
\hline Число больных & 403 & 537 & 453 & 160 \\
\hline $\begin{array}{l}\text { Продолжительность } \\
\text { исследования }\end{array}$ & Июнь 2016 - июль 2017 г. & Март 2017 - май 2018 г. & Май 2017 - июнь 2018 г. & Май 2018 - декабрь 2018 г. \\
\hline Медиана наблюдения, мес & 22,9 & 25,1 & 21,6 & Нет данных \\
\hline $\begin{array}{l}\text { Медиана ВБП } \\
\text { исследовательской группы, } \\
\text { мес }\end{array}$ & $5,2(4,4-5,6)$ & $5,1(4,7-6,2)$ & $4,8(4,3-5,4)$ & 5,5 \\
\hline $\begin{array}{l}\text { Медиана ВБП стандартной } \\
\text { группы, мес }\end{array}$ & $4,3(4,2-4,5)$ & $5,4(4,8-6,2)$ & $4,3(4,2-4,5)$ & 4,6 \\
\hline $\begin{array}{l}\text { Медиана ОВ } \\
\text { исследовательской } \\
\text { группы, мес. }\end{array}$ & $12,3(10,8-15,8)$ & $12,9(11,3-14,7)$ & $10,8(9,2-12,9)$ & 11,3 \\
\hline $\begin{array}{l}\text { Медиана ОВ стандартной } \\
\text { группы, мес. }\end{array}$ & $10,3(9,3-11,3)$ & $10,5(9,3-11,2)$ & $9,7(8,6-10,7)$ & 8,5 \\
\hline
\end{tabular}

В течение длительного времени химиотерапия МКРЛ препаратами платины с ингибиторами топомеразы II, а впоследствии этопозидом составляла основу лечения. Частота ответа при этом составила 60-70\%, однако у большинства пациентов развивается резистентность к лекарственной терапии, что делает прогноз пессимистичным $[8,15]$.

A. Schmittel и соавт. в 2011 г. опубликовали результаты немецкого многоцентрового рандомизированного исследования III фазы по лечению распространенного МКРЛ (РМКРЛ) с применением 2 схем: иринотекан + карбоплатин и этопозид + карбоплатин. Они показали, что режим этопозид + карбоплатин является стандартным, при котором медиана ОВ составила 10 мес против 9 мес при применении схемы карбоплатин + иринотекан [16].

A. Rossi и соавт. в 2012 г. провели систематический обзор и метаанализ рандомизированных исследований по оценке эффективности химиотерапии на основе цисплатина и карбоплатина в качестве терапии 1-й линии при РМКРЛ. Первичной конечной точкой стала ОВ, а вторичными конечными точками - выживаемость без прогрессирования (ВБП), ЧОО и токсичность. В анализ включено 4 исследования с 660 пациента- ми, медиана ОВ для цисплатина составила 9,6 мес, для карбоплатина - 9,4 мес (отношение рисков - ОР 0,108; $95 \%$ доверительный интервал - ДИ 0,92-1,27; $p=0,37)$. Медиана ВБП составила 5,5 и 5,3 мес для цисплатина и карбоплатина соответственно (ОР 1,$10 ; 95 \%$ ДИ 0,94-1,29; $p=0,25)$. ЧОО равнялась 67,1 и $66 \%$ соответственно (ОР 0,98; 95\% ДИ 0,84-1,16; $p=0,83)$. Профиль токсичности значительно отличался для каждого из препаратов. Карбоплатин имеет более низкую почечную, неврологическую и желудочно-кишечную токсичность по сравнению с цисплатином, но более высокую гематологическую. Авторы считают, что различий в эффективности цисплатина или карбоплатина при лечении в 1-й линии РМКРЛ нет, за исключением токсичности [8].

A. Lopez-Chavez и соавт. (2012 г.) также показали, что цисплатин и карбоплатин продемонстрировали сопоставимую эффективность в 1-й линии терапии РМКРЛ. При этом ЧОО составила 67 и $66 \%$ у пациентов, получающих цисплатин + этопозид и карбоплатин + этопозид соответственно [5].

Н. Chen и соавт. (2020 г.) провели сетевой метаанализ применения химиотерапии 1-й линии при РМКРЛ за 20-летний период, начиная с 2000 г. Всего в анализ включено 46 исследова- 
ний, в которых участвовали 11987 пациентов. В 13 исследованиях для этой цели применяли режим этопозид + карбоплатин, который, по мнению авторов, является предпочтительным [18].

Иммуногенность МКРЛ обусловлена экспрессией рецепторов программируемой клеточной смерти PD-1/PD-L1 на опухолевых клетках и иммунных клетках стромы [19]. Кроме того, установлена корреляция с воздействием курения, вызывающего соматические мутации, что сопровождается высокой мутационной нагрузкой [20]. Аутоиммунные паранеопластические синдромы при этом морфологическом варианте наблюдаются в 5\% случаев [21]. В последние годы иммуноонкология совершила переворот в лечении ЗНО, включая РЛ. Первые публикации по применению ИКТ иммунного ответа CTLA4 и PD-1 ниволумаба и ипилимумаба при рецидивирующем МКРЛ появились в 2016 г. [22, 23].

За последние 20 лет и более проведено первое рандомизированное многоцентровое двойное слепое плацебо-контролируемое исследование III фазы IMpower133, показавшее увеличение ОВ у больных РМКРЛ. В исследовании принимали участие 403 пациента с РМКРЛ, ранее не получавших химиотерапию по этому поводу. Статус ECOG оценивался как $0-1$. В исследование включались пациенты с лечеными бессимптомными метастазами в головной мозг. Стратификация исследования осуществлялась по полу, статусу ECOG и наличию метастазов в головной мозг.

Рандомизация осуществлялась на 2 группы лечения. Первая (исследовательская) - 201 пациент. Они получали атезолизумаб 1200 мг в комбинации с карбоплатином AUC 5 мг/мл/мин в 1-й день и этопозидом 100 мг/м² 1-3-й дни каждого 21-дневного цикла на протяжении 4 циклов с последующим назначением атезолизумаба 1 раз в 3 нед. Больные 2-й группы (202 человека) получали плацебо + карбоплатин AUC 5 мг/мл/мин в 1-й день и это-

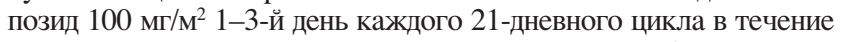
4 циклов с последующим введением плацебо 1 раз в 3 нед.

Лечение проводилось до прогрессирования заболевания, утраты клинической пользы или неприемлемой токсичности [24].

Первичные конечные точки - ОВ и ВБП. Вторичные конечные точки - ЧОО, длительность ответа и безопасность.

Оценка эффекта проводилась каждые 6 нед в соответствии с критериями RECIST 1.1. Медиана возраста составила 64 года.

При промежуточной медиане наблюдения 13,9 мес ОВ составила 12,3 мес $(95 \%$ ДИ 10,8-15,9) у лиц, получающих атезолизумаб, и 10,3 мес в контрольной группе (95\% ДИ $9,3-11,3)$, различия между ними достоверны $(p=0,0069)$. Одногодичная выживаемость составила $51,9 \%$ у пациентов, получающих атезолизумаб, и $39 \%$ в контрольной группе [6].

Медиана ВБП составила 5,2 мес $(95 \%$ ДИ 4,4-5,6) у лиц, получающих атезолизумаб в комбинации с химиотерапией, и $4,3$ мес (95\% ДИ 4,2-4,5; $p=0,0170)$ в группе плацебо в комбинации с химиотерапией.

ЧОО при использовании атезолизумаба + этопозида и карбоплатина составила $60 \%$ (95\% ДИ 53-67), из них полная регрессия констатирована в $2 \%$ случаев, а частичная - в $58 \%$. У больных, получающих плацебо и карбоплатин + этопозид, объективный ответ диагностирован в $64 \%$ случаев (95\% ДИ $57-71)$, полная регрессия отмечена в $1 \%$ наблюдений, а частичная - 63\%. Важным критерием, характеризующим объективный ответ, является его длительность. При этом доля продолжающихся ответов была значительно выше в группе с атезолизумабом $(14,9 \%)$ по сравнению с плацебо $(5,4 \%)$.

У пациентов в группе атезолизумаба одногодичная ВБП составила $12,6 \%$, а при применении только химиотерапии она была практически в 2 раза меньше $-5,4 \%$. Подгрупповой анализ ОВ подтверждает клиническое преимущество добавления атезолизумаба к химиотерапии [25].

Токсичность проводимой комбинации соответствовала известным рискам, характерным для препаратов. Наиболее частыми НЯ 3-4-й степени стали нейтропения - 23\%, анемия $14 \%$, тромбоцитопения - $10 \%$. Иммуноопосредованные НЯ зарегистрированы у 41,4\% больных в группе атезолизумаба, среди них наблюдались чаще всего сыпь - $22 \%$, гипотиреоидизм $-12,6 \%$, а также гепатит $-7,6 \%$. В группе плацебо + химиотерапия их частота составила $24,5 \%[10,25]$.

В исследовании показано, что уровень PD-L1 не влияет на преимущество ОВ, в связи с чем нет необходимости опреде- лять его уровень при назначении атезолизумаба в комбинации с химиотерапией [25].

Добавление атезолизумаба к этопозиду + карбоплатину в 1-й линии терапии РМКРЛ сопровождается значительным увеличением как ОВ, так и ВБП. При этом более $50 \%$ пациентов прожили 1 год. Полученные данные позволили рассматривать комбинацию атезолизумаба с карбоплатином и этопозидом в качестве нового стандарта терапии 1-й линии при РМКРЛ [25].

S. Liu и соавт. в 2021 г. опубликовали обновленный анализ OB с дополнительным 9-месячным наблюдением клинического исследования IMpower133. При этом медиана наблюдения составила 22,9 мес. Авторы сообщили о результатах ОВ в зависимости от мутационной нагрузки опухоли в крови (вТМВ), экспрессии PD-L1 и локализации метастазов, а также о безопасности [24].

ОВ через 12 мес увеличилась на $12,9 \%$ в группе атезолизумаб + химиотерапия относительно пациентов, получающих плацебо + химиотерапию, составляя при этом 51,9 и $39,0 \%$ соответственно. Медиана ОВ также составила 12,3 и 10,3 мес при применении атезолизумаба в комбинации с карбоплатином и этопозидом и плацебо и химиотерапии соответственно (ОР 0,$76 ; 95 \%$ ДИ 0,60-0,95). Аналогичная ситуация наблюдалась и через 18 мес: 34 и 21\% больных были живы в группах атезолизумаба в комбинации с карбоплатином и этопозидом и плацебо и химиотерапии.

Медиана ВБП при обновленном анализе равна 5,2 мес в группе атезолизумаб + этопозид с платиной и 4,3 мес в группе плацебо + химиотерапия (ОР 0,77; 95\% ДИ 0,63-0,95); табл. 1.

При анализе прогрессирования этот процесс констатирован в существующих очагах в 57,7 и в $64,9 \%$ случаев в группе атезолизумаба в комбинации с химиотерапией и группе плацебо с химиотерапией соответственно. У 42,8 и $49 \%$ пациентов указанных групп соответственно появились новые очаги поражения. Наиболее частыми локализациями новых метастазов являлись центральная нервная система, легкие, лимфатические узлы и печень. Комбинация указанных поражений наблюдалась у 20,9 и $28,2 \%$ пациентов исследовательской и контрольной групп соответственно.

НЯ, обусловленные лечением, были сопоставимы с безопасностью, представленной при первичном анализе [10]. Иммуноопосредованные НЯ наблюдались у $20,2 \%$ пациентов 1-й группы с атезолизумабом и у 5,6\% у больных 2-й группы с плацебо. Наиболее частыми иммунными побочными эффектами стали сыпь - 20,2\% против $10,7 \%$, гипотиреоз - $12,6 \%$ против $0,5 \%$, гепатит $-70,6 \%$ против $4,6 \%$.

Авторы приходят к мнению о том, что обновленные результаты ОВ после дополнительных 9 мес наблюдения демонстрируют клиническое преимущество атезолизумаба в комбинации с этопозидом и карбоплатином относительно плацебо + карбоплатин и этопозид при применении в 1-й линии терапии РМКРЛ. Добавление атезолизумаба к химиотерапии не увеличивает токсичность и не ухудшает качество жизни пациента. Клиническая польза атезолизумаба совместно с этопозидом и карбоплатином не зависит от статуса биомаркеров опухоли в крови в TMB и PD-L1 [24].

K. Higgins и соавт. (2020 г.) показали, что добавление атезолизумаба к схеме химиотерапии этопозид + карбоплатин увеличивает на 9,7 мес медиану времени до прогрессирования в центральную нервную систему. В группе с атезолизумабом медиана составила 20,2 мес, в то время как с плацебо она равна 10,5 мес (OР 0,$66 ; 95 \%$ ДИ 0,44-1,0; $p<0,046)$ [17].

Применение ИКТ иммунного ответа PD-1 ниволумаба или пембролизумаба при рецидивирующем и метастатическом РЛ в 3-й или более поздней линии терапии позволило получить клинический ответ у 12-20\% пациентов, при этом медиана его продолжительности составила 17,2 мес [23, 26]. Эти данные позволили получить ускоренное одобрение Управления по контролю пищевых продуктов и лекарств в США для лечения МКРЛ в качестве терапии 3-й линии.

F. Facchinetti и соавт. (2020 г.) представили систематический обзор и метаанализ рандомизированных клинических исследований по оценки эффективности добавления ИКТ к стандартной схеме химиотерапии при РМКРЛ [27]. Авторы выявили 4 клинических исследования, дизайн результатов которых представлен в табл. 2. 
В эти исследования включены 1553 пациента в период с июня 2016 по декабрь 2018 г. Средний возраст составил 62-65 лет, статус ECOG 0 - у 31,7\%, ECOG 1 - 68,3\% пациентов. Среди них мужчин - 64,4\%. Карбоплатин получали $80,5 \%$, а цисплатин $19,5 \%$ больных. На момент включения метастазы в головной мозг наблюдались у 10,4\% пациентов, а метастазы в печень - у 39,3\%. Характеристики больных экспериментальных и контрольных групп во всех исследованиях были хорошо сбалансированы.

Добавление ИKT PD-1/PD-L1 к химиотерапии, состоящей из платины и этопозида в терапии 1-й линии при РМКРЛ, во всех исследованиях обеспечивало статистически значимые преимущества по ОВ (ОР 0,76; 95\% ДИ 0,068-0,85; $p<0,00001)$. Медиана ОВ варьировала от 8,5 до 10,5 мес в контрольной группе и от 10,8 до 12,9 мес в экспериментальной (см. табл. 2).

Анализ ВБП во всех 4 исследованиях показал, что добавление ИKТ PD-1/PD-L1 к химиотерапии обеспечивает статистически значимые преимущества (ОР 0,75; 95\% ДИ 0,68-0,84; $p<0,00001)$, причем в контрольных и экспериментальных группах медиана ВБП колебалась от 4,8 до 5,5 мес соответственно (см. табл. 2). Во всей популяции исследования добавление ИКT PD-1/PD-L1 к стандартному режиму химиотерапии при РМКРЛ позволило получить статистически значимое увеличение шансов ответа (ОР 1,28; 95\% ДИ 1,04-1,57; $p=0,02)$, а достоверное увеличение ответов получено при добавлении иммунопрепаратов к химиотерапии этопозид + платина. В целом ЧОО составила $59 \%$ у лиц контрольной и 64,7\% - исследовательской групп, за исключением исследования IMpower133. При этом полные ответы констатированы чаще у пациентов экспериментальных групп, составляя 2,4\%, а при стандартном лечении они наблюдались у 0,9\% больных.
Оценка безопасности проводимой терапии с добавлением ИKT PD-1/PD-L1 установила количественное увеличение побочных эффектов. Среди НЯ токсичность всех степеней чаще встречалась в экспериментальной группе (OP 2,89; $95 \%$ ДИ $1,13-7,38 ; p=0,03)$. При этом значимых различий 3 и 4-й степени токсичности не наблюдалось. Среди иммунных токсических явлений наиболее часто встречались дерматит/сыпь $10,8 \%$ и дисфункция щитовидной железы - 16,3\% .

Авторы приходят к выводу, что добавление ИКТ PD-1/ $\mathrm{PD}-\mathrm{L} 1 \mathrm{\kappa}$ основной схеме химиотерапии при проведении 1-й линии терапии РМКРЛ является эффективной и безопасной опцией. ОВ через 12, 18 и 24 мес составила 50,2, 32 и $22,3 \%$ соответственно. Полученные результаты являются основанием для включения ИKT PD-1/PD-L1 в стандарт лечения пациентов с РМКРЛ [27].

\section{Заключение}

Добавление атезолизумаба к химиотерапии по схеме карбоплатин + этопозид показывает высокую эффективность у пациентов с РМКРЛ. Получена полная клиническая и морфометаболическая регрессия опухоли. ОВ и ВБП у больного из приведенного примера составили 14 мес. Применение

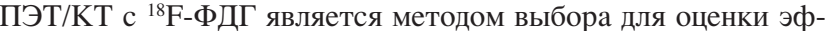
фективности иммунотерапии. Качество жизни пациента при этом остается удовлетворительным. Переносимость терапии приемлемая.

Конфликт интересов. Авторы заявляют об отсутствии конфликта интересов.

Conflict of interests. The authors declare no conflict of interest.

\section{תumepamypa/References}

1. Globacan 2018. Available at: https://gco.iarc.fr// Accessed: 15.03.2021.

2. Злокачественные новообразования в России в 2019 году (заболеваемость и смертность). Под ред. А.Д. Каприна, В.В. Старинского, А.О. Шахзадовой. М.: МНИОИ им. П.А. Герцена - филиал ФГБУ «НМИЦ радиологии» Минздрава России, 2020 [Ed. AD Kaprin, WV Starinskii, AO Shakhzadova. Malignant neoplasms in Russia in 2019 (morbidity and mortality). Moscow: P. Hertsen Moscow Oncology Research Institute - the branch of National Medical Research Radiological (entre, 2020 (in Russian)].

3. Van Meerbeeck JP, Fennell DA, De Ruysscher DK. Small-cell lung cancer. Lancet. 2011;378:1741-55. DOl:10.1016/50140-6736(11)60165-7

4. Bernhardt EB, Jalal SI. Small cell lung cancer. Cancer Treat Res. 2016;170:301-22. D01:10.1007/978-3-319-40389-2 14

5. Lopez-Chavez A, Sandler A. Systemic issues in small cell lung cancer. Curr Probl Cancer. 2012;36(3):131-55. D01:10.1016/j.currproblcancer.2012.03.004

6. National Comprehensive Cancer Network. NCCN Clinical Practice Guidelines in Oncology: Small Cell Lung Cancer (Version 1.2019), 2019. Availableat:https://tomocenter.com.ua/wp-content/uploads/small-cell-lung-cancer.pdf. Accessed:20.03.2021.

7. Armstrong SA, Liu SV. Dashing decades of defeat: Long anticipated advances in the first-line treatment of extensivestage small cell lung cancer. Curr Oncol Reports. 2020;22:20. D01:10.1007/s11912-020-0887-y

8. Rossi A, Di Maio M, Chiodini P, et al. Carboplatin- or cisplatin-based chemotherapy in first-line treatment of smallcell lung cancer: The COCIS meta-analysis of individual patient data. J Clin Oncol. 2012;30:1692-8. DOl:10.1200/JC0.2011.40.4905

9. Foster NR, Renfro LA, Schild SE, et al. Multitrial evaluation of progression-free survival as a surrogate end point for overall survival in first-line extensive-stage small-cell lung cancer. J Thorac Oncol. 2015;10:1099-106. DOl:10.1097/JT0.0000000000000548

10. Horn L, Mansfield AS, Szczesna A, et al. First-line atezolizumab plus chemotherapy in extensive-stage small-cell lung cancer. N Engl J Med. 2018:379:2220-9. D01:10.1056/NEJMoa1809064

11. Antonia SJ, Lopez-Martin JA, Bendell J, et al. Nivolumab alone and nivolumab plus ipilimumab in recurrent smallcell lung cancer (CheckMate 032): A multicentre, open-label, phase 1/2 trial. Lancet Oncol. 2016;17:883-95. DO1:10.1016/51470-2045(16)30098-5

12. Paz-Ares $L$, Dvorkin $M$, Chen Y, et al. Durvalumab plus platinum-etoposide versus platinum - etoposide in first-line treatment of extensive-stage small-cell lung cancer (CASPIAN): A randomised, controlled, open-label, phase 3 trial. Lancet. 2019:394:P1929-39. D01:10.1016/S0140-6736(19)32222-6

13. TECENTRIQ (Atezolizumab) [Summary of Product Characteristics]. Grenzach-Wyhlen, Germany, Roche Registration $\mathrm{GmbH}, 2019$.

14. Ott PA, Elez E, Hiret $S$, et al. Pembrolizumab in patients with extensive-stage small-cell lung cancer: Results from the phase lb KEYNOTE-028 study. J Clin Oncol. 2017;35:3823-9. D01:10.1200/JC0.2017.72.5069

15. Eckardt JR, Von Pawel J, Pujol IL, et al. Phase III study of oral compared with intravenous topotecan as second-line therapy in small-cell lung cancer. J Clin Oncol. 2007;25:2086-92. D01:10.1200/JC0.2006.08.3998

16. Schmittel A, Sebastian M, Fischer von Weikersthal L, et al. A German multicenter, randomized phase III trial comparing irinotecan-carboplatin with etoposide-carboplatin as first-line therapy for extensive-disease small-cell lung cancer. Ann Oncol. 2011;22:1798-804. D01:10.1093/annonc/mdq652
17. Higgins KA, Curran WJ Jr. Liu SV, et al. Patterns of Disease Progression after Carboplatin/Etoposide + Atezolizumab in Extensive-Stage Small-Cell Lung Cancer (ES-SCLC). Int J Radiat Oncol Biol Phys. 2020;108(5):1398.DO1:10.1016/j.jirobp.2020.09.020

18. Chen H, Horita N, Ito K, et al. Affiliations expand Systematic review of first-line chemotherapy for chemo-naive extensive-stage small-cell lung cancer: network meta-analysis. Ther Adv Med Oncol. 2020;12:1758835920965841. DOl:10.1177/1758835920965841

19. Schultheis AM, Scheel AH, Ozretić L, et al. PD-L1 expression in small cell neuroendocrine carcinomas. Eur J Cancer. 2015;51:421-6. DOl:10.1016/j.eja.2014.12.006

20. Alexandrov LB, Nik-Zainal $S$, Wedge $D C$, et al. Signatures of mutational processes in human cancer. Nature. 2013:500:415-21. D01:10.1038/nature12477

21. Pelosof LC, Gerber DE. Paraneoplastic syndromes: An approach to diagnosis and treatment. Mayo Clin Proc 2010;85:838-54. D0l:10.4065/mcp.2010.0099

22. Pujol IL, Greillier L, Audigier-Valette C, et al. A randomized non-comparative phase II study of anti-programmed cell death-ligand 1 atezolizumab or chemotherapy as second-line therapy in patients with small cell lung cancer: Results from the IFCT-1603 trial. J Thorac Oncol. 2019;14:903-13. DO1:10.1016/j.jtho.2019.01.008

23. Ready N, Farago AF, de Braud F, et al. Third-Line Nivolumab Monotherapy in Recurrent SCLC: CheckMate 032.J Thorac Oncol. 2019:14:237-44.DOl:10.1016/jitho.2018.10.003

24. Liu SV, Reck M, Mansfield AS, et al. Updated Overall Survival and PD-L1 Subgroup Analysis of Patients With Extensive-Stage Small-Cell Lung Cancer Treated With Atezolizumab, Carboplatin, and Etoposide (IMpower133). J Clin Oncol. 2021;39(6):619-30. D01:10.1200/JC0.20.01055

25. Reck M, Liu SV, Mansfield AS, et al. IMpower133: Updated overall survival (OS) analysis of first-line (1L) atezolizumab (atezo) + carboplatin + etoposide in extensive-stage SCLC (ES-SCLC). Ann Oncol. 2019;30(Suppl. 5):V710-1. DOl:10.1093/annonc/mdz264

26. Chung HC, Piha-Paul SA, Lopez-Martin J, et al. Pembrolizumab After Two or More Lines of Previous Therapy in Patients With Recurrent or Metastatic SCLC: Results From the KEYNOTE-028 and KEYNOTE-158 Studies. I Thorac Oncol 2020;15:618-27. DOl:10.1016/j.jtho.2019.12.109

27. Facchinetti F, Di Maio M, Tiseo M. Adding PD-1/PD-L1 Inhibitors to Chemotherapy for the First-Line Treatment of Extensive Stage Small Cell Lung Cancer (SCLC): A Meta-Analysis of Randomized Trials. Cancers (Basel). 2020;12(9):2645 DOl:10.3390/cancers 12092645

28. Paz-Ares L, Dvorkin M, Chen Y, et al. Durvalumab $+/$ - tremelimumab + platinum-etoposide in first-line extensivestage SCLC (ES-SCLC): Updated results from the phase III CASPIAN study. I Clin Oncol. 2020;38:9002. DOl:10.1200/JCO.2020.38.15 suppl.9002

29. Rudin $C M, A$ awad MM, Navarro $A$, et al. Pembrolizumab or placebo plus etoposide and platinum as first-line therapy for extensive-stage small-cell lung cancer. J Clin Oncol. 2020;38:2369-79. DOl:10.1200/JC0.20.00793

30. Rudin CM, Awad MM, Navarro A, et al. KEYNOTE-604: Pembrolizumab (pembro) or placebo plus etoposide and platinum (EP) as first-line therapy for extensive-stage (ES) small-cell lung cancer (SCLC) I Clin Oncol. 2020;38:9001. DO1:10.1200/JC0.2020.38.15_suppl.9001 